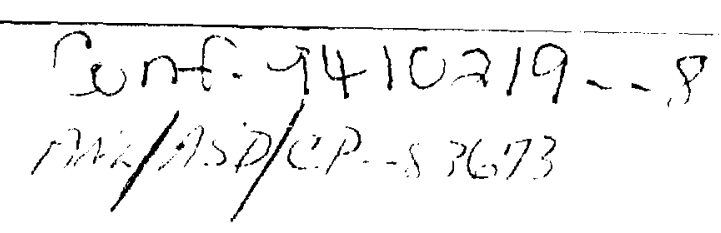

\title{
High Beam Current Shut-off Systems in the APS Linac and Lew Energy Transfer Line*
}

\author{
X. Wang, M. Knott, and A. Lumpkin \\ Advanced Photon Source \\ Argonne National Laboratory \\ 9700 S. Cass Ave. \\ Argonne, IL 60439
}

\section{DISCI,AIMER}

This report was prepared as an account of work sponsored by an agency of the United States Government. Neither the United States Government nor any agency thereof, nor any of their employees, makes any warranty, express or implied, or assumes any legal liability or responsibility for the accuracy, completeness, or usefulness of any information, apparatus, product, or process disclosed, or represents that its use would not infringe privately owned rights. Reference herein to any specific commercial product, process, or service by trade name, trademark, manufacturer, or otherwise does not necessarily constitute or imply its endorsement, recommendation, or favoring by the United States Government or any agency thereof. The views and opinions of authors expressed herein do not necessarily state or reflect those of the United States Governinent or any agency thereof.

\section{*Work supported by the U.S. Department of Energy, Office of Basic Energy Sciences, under Contract No. W-31-109-ENG-38.}




\title{
High Beam Current Shut-off Systems in the APS Linac and Low Energy Transfer Line ${ }^{1}$
}

\author{
X. Wang, M. Knott, and A. Lumpkin \\ Argonne National Laboratory, Argonne, Illinois 60439
}

\begin{abstract}
Two independent high beam current shut-off current monitoring systems (BESOCM) have been installed in the APS linac and the low energy transport line to provide personnel safety protection in the event of acceleration of excessive beam currents. Beam current is monitored by a fast current transformer (FCT) and fully redundant supervisory circuits connected to the Access Control Interlock System (ACIS) for beam intensity related shutdowns of the linac. One FCT is located at the end of the positron linac and the other in the low energy transport line, which directs beam to the positron accumulator ring (PAR). To ensure a high degree of reliability, both systems employ a continuous selfchecking function, which injects a test pulse to a single-turn test winding after each "real" beam pulse to verify that the system is fully functional. The system is designed to be failsafe for all possible system faults, such as loss of power, open or shorted signal or test cables, loss of external trigger, malfunction of gated integrator, etc. The system has been successfully commissioned and is now a reliable part of the total ACIS.
\end{abstract}

\section{INTRODUCTION}

The BESOCM system is designed to prevent the unintentional acceleration of high beam currents that could result in unexpected and hazardous radiation fields. Two BESOCM systems have been installed at locations shown in Fig. 1. The current design is based on detecting beam current of a single 30ns macropulse in the positron linac and linac-to-PAR transport line (LTP)(1). Should measured beam current exceed the preset trip levels, accelerator operation is immediately shut down through hard-wired trip circuits (i.e. no software links) interfaced to the ACIS.

The trip levels of two systems specified by the APS Accelerator System Division Radiation Safety Policy Committee are (2):

Positron linac BESOCM $25 \mathrm{nC} /$ macropulse for electrons only

LTP BESOCM $0.67 \mathrm{nC} /$ macropulse for electrons or positrons

The main purpose of the positron linac BESOCM is to limit the radiation level for all downstream locations in case of the positron target failure. It is understood that the positron current level at this location will never reach a level high enough to cause safety concerns. Therefore, it is not necessary to set a positron trip level for the system.

A BESOCM trip will occur if the total charge in one macropulse exceeds the trip level. The safety envelopes are, however, based on averaging the current over some

1 Work supported by U.S. Department of Energy, Office of Basic Energy Sciences, under contract no.W-31-109-ENG-38. 
time period. Because of this, a BESOCM trip does not indicate a violation of the safety envelope, but rather that a condition has been detected, which might have resulted in a violation of the safety envelope if it had been allowed to persist.

The high reliability of the system is ensured by using two completely redundant channels in each system starting from the FCT all the way through to the ACIS connectors. Furthermore, each system employs a continuous self-checking function to test for various failure conditions. The accelerated beam will be inhibited if a fault condition is detected.

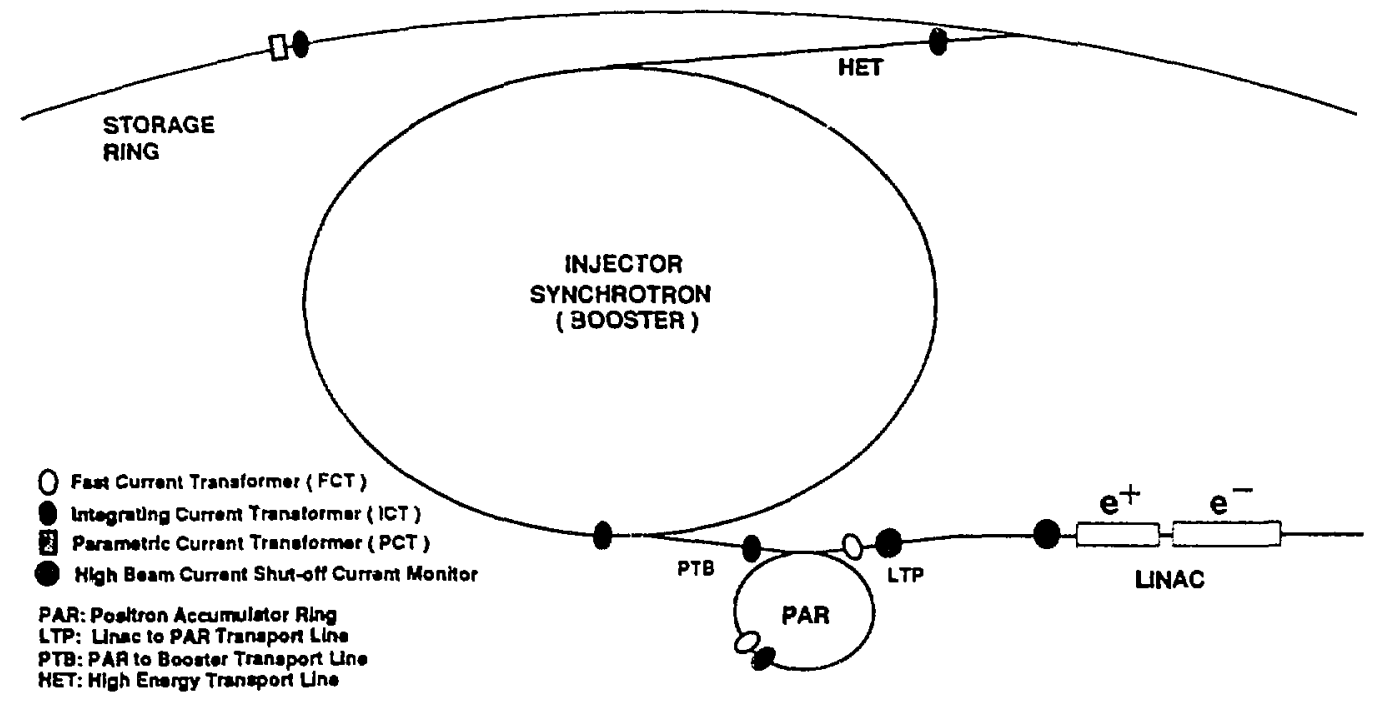

Fig. 1 Locations of the beam current monitors in the APS

\section{SYSTEM DESCRIPTION}

The design and basic operation of the systems presently installed will be described by referring to the block diagram in Fig. 2 and the system timing diagram in Fig. 3.

The beam total charge measurement for pulsed beam of charged particles is performed by an FCT and a fast gated integrator described in (3) and (4). This gated integrator, with its fast response, well-defined output, and very small droop rate, makes it possible to accurately measure the total charge of the single $30 \mathrm{~ns}$ linac, macropulse and to provide a stable DC level proportional to the charge for limitcheckings.

The output signal from the preamplifier is integrated by the gated integrator during a gate interval that is controlled by the timing and control unit. The external trigger signal to the timing and control unit is derived from the linac modulator \#1 trigger so that the gate pulse is synchronized to the 2 to $60 \mathrm{~Hz}$ linac firing. It was determined that there is a significant delay plus rise time associated with the turn-on of the modulators. Based on this, a 1.5- $\mu$ s delay is added between the modulator \#1 trigger and the leading edge of the gate pulse for beam signal as shown in Fig. 3. In 


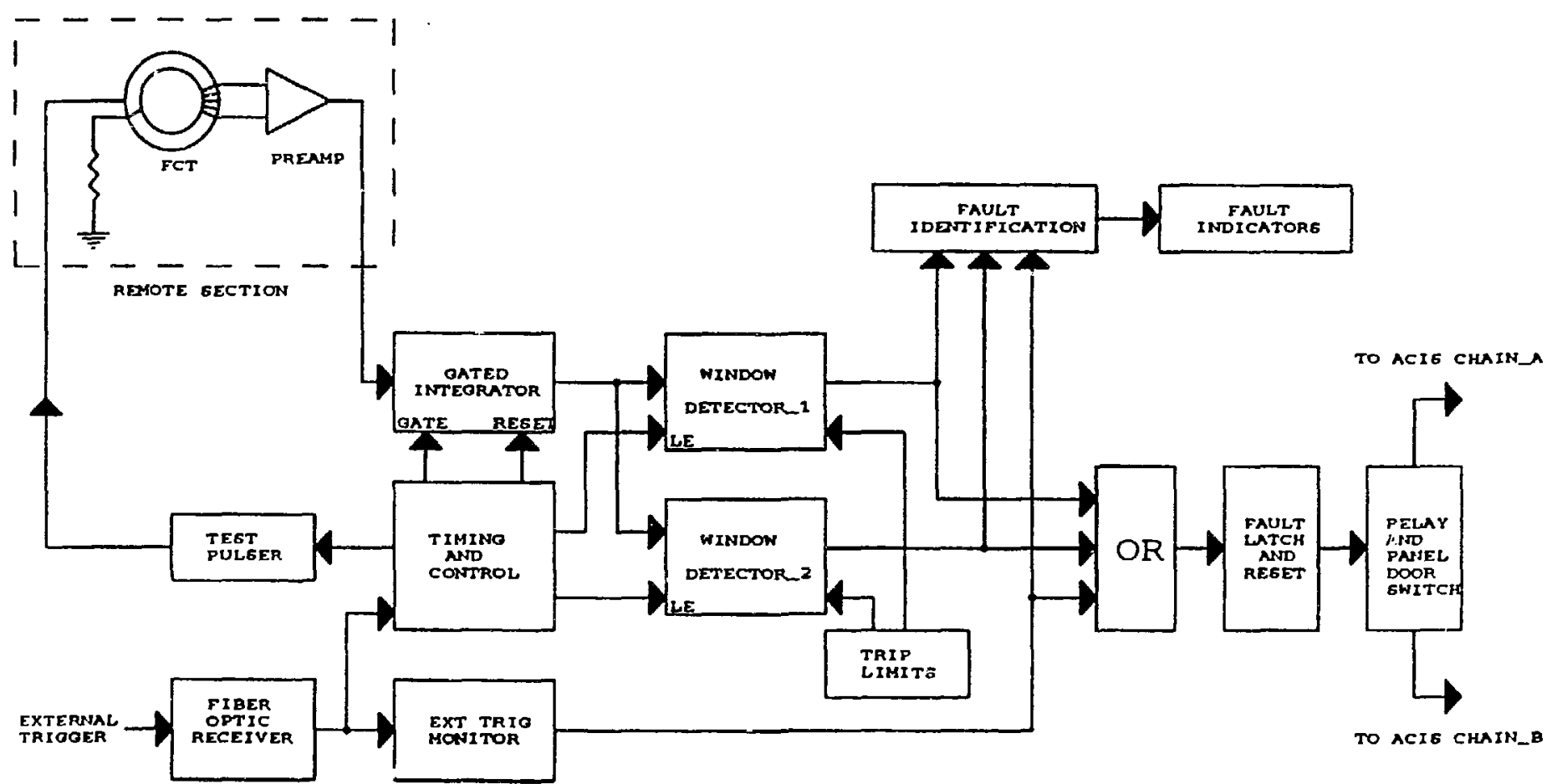

Fig. 2 Block diagram of the one channel BESOCM system 
addition, the gate is set to be wide enough ( $6.5 \mu \mathrm{s}$ ) to cover the time period when beam could be injected from the gun and overlap the if power pulse in the accelerators (5). The system also employs an external trigger monitor designed to check for the presence of the external trigger signal. If the external trigger is absent for longer than one second, a fault will be generated to disable linac operation.

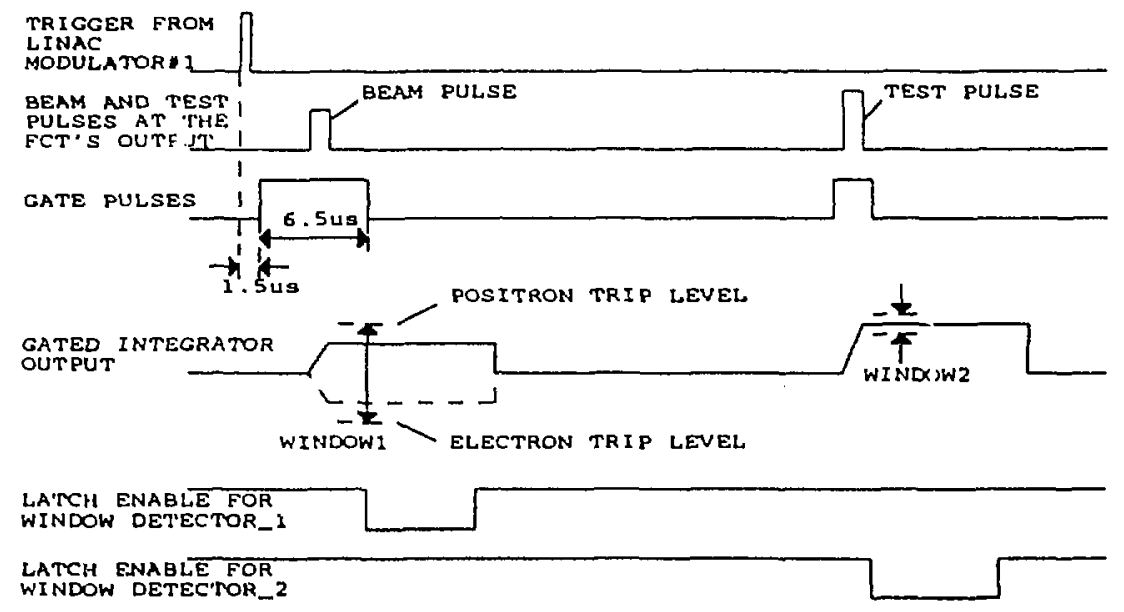

Fig. 3 Timing diagram of the BESOCM system

As illustrated in Fig. 3, the bipolar gated integrator has a positive or negative output DC level proportional to the positron or electron beam total charge, respectively. The integrator's output $\mathrm{DC}$ level is monitored by both window detector 1(WD1) and window detector 2 (WD2), each enabled in a different time slot. The WD1 has an upper limit corresponding to the positron trip level and a lower limit corresponding to the electron trip level. It is used to detect an out-of-range beam signal, when enabled after the gate window for the beam signal is closed and before the gated integrator's output is reset to zero. Approximately $30 \mu \mathrm{s}$ after the beam pulse, a test pulse also synchronized to the linac beam is sent to a single-turn test winding in the current transformer. The detected signal from the test winding is integrated by the same gated integrator and compared to closely-set high and low limits of the WD2. When a failure condition occurs, such as malfunction of the gated integrator, open or shorted signal or test cables, etc., the gated integrator's output DC level for the test puise will be outside the preset limits. It is important to note that the system is always under continuous test even without beam.

If any one of the four limits of the two window detectors is exceeded during the operation, the interlock relay is opened and the ACIS will shut down all linac systems.

All system faults are latched, identified, and indicated on the electronics chassis' front panel. The critical checkpoints in the system are buffered for access from the front panel. The fault can be reset locally or remotely via the control system. Photographs of the system's front and rear panels are shown in Fig. 4 and Fig. 5. The 
system is fully redundant with two identical channels in each chassis. Two independent power supplies are provided for the separate channels. The front panel door shown in Fig. 4 has to be locked to close the interlock loop. The controls behind the door are for setting the trip levels and adjusting the timing variables. The adjustments can only be made by authorized personnel.

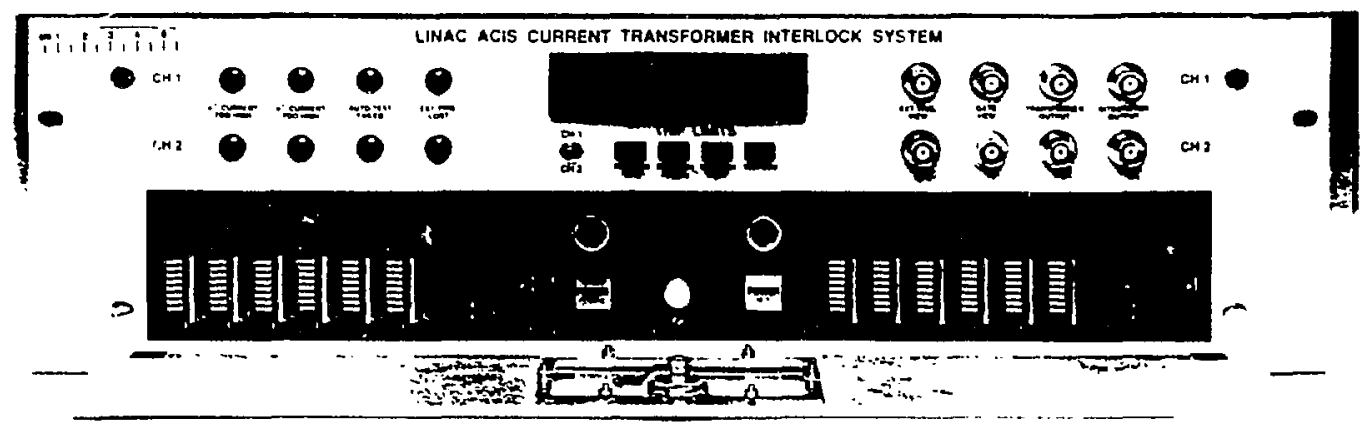

Fig. 4 The front panel of the BESOCM electronics chassis

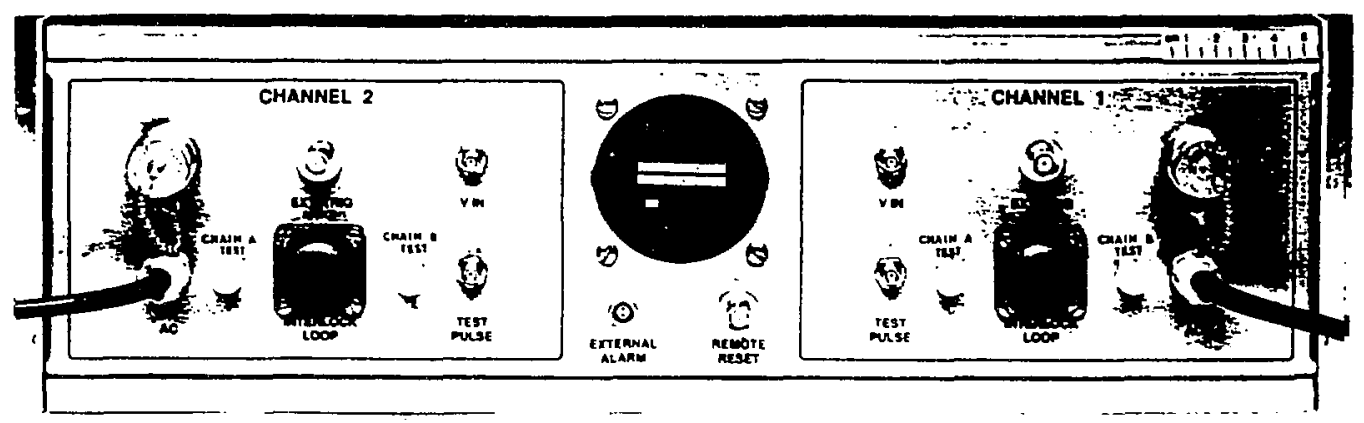

Fig. 5 The rear panel of the BESOCM electronics chassis

\section{OPERATIONAL EXPERIENCE}

The positron linac and LTP BESOCM systems have been installed and operating since February, 1994. All system functions were tested as part of the ACIS validation test procedure before operations started. Overall system reliability is excellent. Both systems have performed the job as required and aborted in the fail-safe mode. A typical operational cycle with real linac electron beam (the APS injector sub-systems are currently running on the electron beam only) is shown in Fig. 6. A 1.5- $\mu$ s gate delay and 6.5- $\mu$ s gate width are indicated.

The only problem encountered which remains to be resolved is the noise-related false trips generated by the LTP BESOCM system especially during the early commissioning stage. The positron linac BESOCM system was almost never tripped 
because of high trip levels. As noted in a previous section, the gate window of the gated integrator is set for a long period $(6.5 \mu \mathrm{s})$ to ensure that a linac beam triggered at any time during the linac if pulse active time can be monitored by the gated integrator, and the trip level set for the LTP BESOCM is only $670 \mathrm{pC}$. This means that the gated integrator has to integrate the noise over a $6.5-\mu \mathrm{s}$ window while it has only $30 \mathrm{~ns}$ to integrate real beam signal. It is clear that noise can sometimes dominate the integral and produce a false trip. The high voltage PAR kicker pulse power supplies near the LTP BESOCM current transformer housing were identified as the main noise source. The intermittent kicker noise picked up by the FCT has a noise pattern shown in Fig. 7. It consists of a high frequency burst which is integrated with no effect, and a clean low frequency sinewave following the initial high frequency transient, which results in a DC offset and sometimes a trip. To solve the problem, the shielding and grounding of the kicker power supplies were modified and improved. This reduced the number of false trips. Unfortunately, the results have been unstable due to the complicated kicker grounding structures. Some upgrades from the BESOCM system side have been discussed and will be implemented soon, including using heavier and more thorough shielding for the LTP FCT and triaxial cable to transmit the signal to the instrument room, shortening the gate window slightly to eliminate the majority of noise effect, and equipping the system with a firmware-based method of averaging the beam current over some time period within the safety envelope.

\section{CONCLUSION}

The high beam current shut-off systems were developed to eliminate the possibility of accidental radiation exposure due to unintentional acceleration of high beam currents. This capability allows management to define a safety envelope of operation that contributes to significantly improved protection at the accelerator. The system's high relialiability is ensured by employing hardwired design, redundant monitoring channels, built-in self-checking functions, and many other fail-safe features. The system described satisfies the present operational requirements. Some system upgrades are to be implemented.

\section{ACKNOWLEDGMENTS}

The authors wish to thank Bob Hettel at SSRL for the helpful information and discussions; John Galayda, Michael Borland, and Glenn Decker for their support during the commissioning; and Richard Voogd, Peter Nemenyi and others for their outstanding work during construction of the systems. 


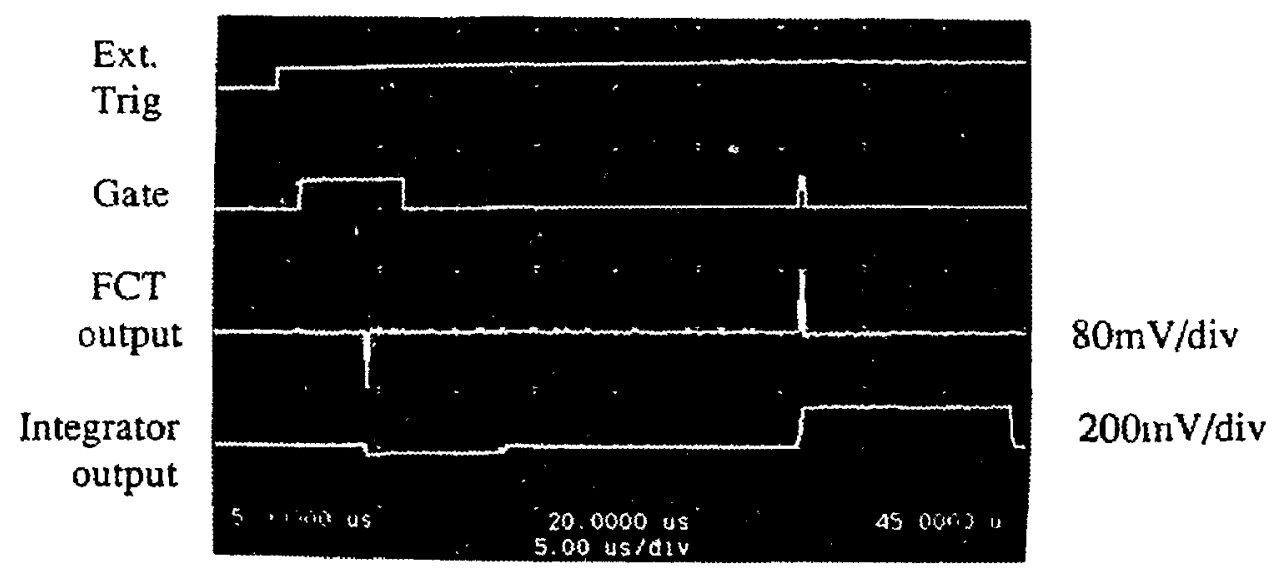

Third trace: $80 \mathrm{mV} / \mathrm{div}$

Bottom trace: 20lmVidis

Fig. 6 BESOCM signal traces

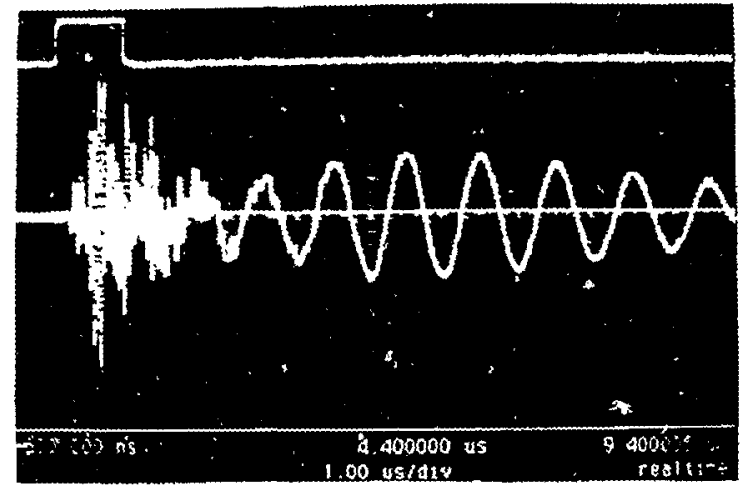

$50 \mathrm{mV} / \mathrm{div}$

Fig. ? The PAR kicker noise

\section{REFEREXCES}

1. R. Hettel, private communication.

2. J. Galayda, M. Borland. privite communicition.

3. X. Wang, F. Lenkszus and E. R.tela, "Design and Commissioning of the APS

Beam Charge and Current Vorivers" heve puedings.

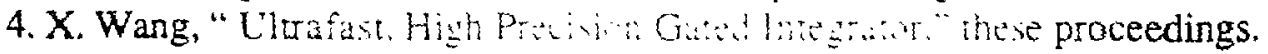

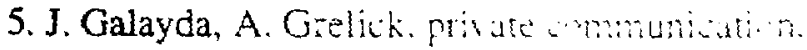

